\title{
Effects of Intramuscular or Bioadhesive Buccal Testosterone Treatment on Antioxidant Systems in Secondary Hypogonadism
}

\author{
Mancini $A^{1 *}$, Raimondo $S^{1}$, Di Segni $C^{1}$, Persano $M^{1}$, Cammarano $M^{1}$, Pontecorvi $A^{1}$, Festa $R^{2}$, Tiano $L^{3}$, Silvestrini $A^{4}$ and Meucci $E^{4}$ \\ ${ }^{1}$ Department of Medical Sciences, Division of Endocrinology, The Catholic University School of Medicine, Rome, Italy \\ ${ }^{2}$ Department of Clinical and Molecular Sciences, Polytechnic University of Marche, Ancona, Italy \\ ${ }^{3}$ Institute of Biochemistry, Polytechnic University of the Marche, Ancona, Italy \\ ${ }^{4}$ Institute of Biochemistry and Clinical Biochemistry, Catholic University of the Sacred Heart, Rome, Italy
}

\begin{abstract}
From cross-sectional studies in healthy men, lower plasma total testosterone levels seem to be associated with hyperinsulinemia, decreased glucose tolerance, and a higher level of cardiovascular risk factors. Despite in vitro and in vivo experiments suggest a key role of testosterone in modulating antioxidant systems in different tissues, few data are reported in humans. Extending our previous results, we show that treatment with testosterone, both in intramuscular or bioadhesive buccal formulations, increase plasma levels of Coenzyme Q10, lipophilic antioxidant, and total antioxidant capacity, measured with colorimetric method, in patients with secondary hypogonadism. Hypogonadism could represent a condition of oxidative stress, in turn related with augmented cardiovascular risk in such patients.
\end{abstract}

Keywords: Hypogonadism; Hyperinsulinemia; Testosterone

\section{Introduction}

From cross-sectional studies in healthy men, lower plasma total testosterone $(\mathrm{T})$ levels seem to be associated with hyperinsulinemia, decreased glucose tolerance, and a higher level of cardiovascular risk factors [1-4]. A relatively low blood concentration of testosterone in the older men may have adverse effects, promoting atherosclerosis, and explain the higher incidence of coronary heart disease in the male [5]. Therefore, male hypogonadism can be associated to metabolic syndrome and increased cardiovascular risk [6]. Oxidative stress (OS), due to an imbalance between reactive oxygen species (ROS) and antioxidant defense, is a possible mechanism involved both in complications of metabolic syndrome and male infertility [7]. It has already been recognized that seminal Total Antioxidant Capacity (TAC, which reflects non enzymatic antioxidants) significantly correlates with $\mathrm{FSH}, \mathrm{LH}$, free-T3 (fT3), but not with testosterone [8]. In previous works we have demonstrated alterations of plasma coenzyme Q10 (CoQ10, lipidic antioxidant, also endowed with bioenergetic properties) in pituitary diseases, such as acromegaly or secondary hypothyroidism: in particular, a significant inverse correlation between plasmatic values of CoQ10 and thyroid hormones, fT3 and free-T4 (fT4), was observed; in patients with acromegaly, plasmatic value of CoQ10 was low [7]. Moreover, a relationship between sex hormones and plasmatic TAC was already observed. Finally, we have demonstrated that Testosterone treatment induced a significant change both in CoQ10 level and LAG in secondary hypogonadism [9].

To further investigate the role of gonadal steroids in the regulation of systemic antioxidants, we have determined blood plasma CoQ10 and TAC in a group of post-surgical hypogonadal patients, before and after treatment with two different testosterone formulations.

\section{Materials and Methods}

20 patients, aged $20-70 \mathrm{yrs}$, were studied at 6-12 months after trans-sphenoidal operation for pituitary tumors (prolactinomas or non secreting tumors of the hypothalamus-pituitary region). All were hypopituitaric, but exhibited a normalization of thyroidal and adrenal hormone values with replacement therapy $(50-100 \mathrm{mcg}$ of L-thyroxine daily and 20-30 mg of hydrocortisone daily). Replacement therapy for hypogonadism was performed, randomly assigning the patients to two groups: testosterone enantate ( $250 \mathrm{mg}$ i.e. every 3 weeks, group A, $\mathrm{n}=15$ ) bioadhesive buccal testosterone ( $30 \mathrm{mg}$ /daily, group $\mathrm{B}, \mathrm{n}=5) .10$ normal subjects, aged 30-55 yrs, were studied as control group.

\section{Main outcome measures}

CoQ10 levels were measured by a well recognized HPLC (highperformance liquid chromatography) method [10]. The method is based on oxidation of CoQ10 in the sample by treating it with parabenzoquinone followed by extraction with 1-propanol and direct injection into the HPLC apparatus. Preoxidation of the sample ensures quantification of total CoQ10 by U.V. detection. This method achieves a linear detector response for peak area measurements over the concentration range of 0.05-3.47 $\mu \mathrm{M}$. Diode array analysis of the peak was consistent with CoQ10 spectrum. Supplementation of the samples with known amounts of CoQ10 yielded a quantitative recovery of 96-98.5\%; the method showed a level of quantitation of $1.23 \mathrm{nmol}$ per HPLC injection (200 $\mu \mathrm{l}$ of propanol extract containing $33.3 \mu \mathrm{l}$ of plasma). A good correlation was found with a reference electrochemical detection method ( $r=0.99, p<0.0001)$. Within run precision showed a CV\% of 1.6 for samples approaching normal values $(1.02 \mu \mathrm{M})$. Dayto-day precision was also close to $2 \%$. Moreover, CoQ10 values were related to plasma cholesterol concentration, measured by a cholesterol oxidase enzymatic test.

Total Antioxidant Capacity (TAC) was evaluated, with a modification of the method developed by Rice-Evans and Miller [11], as previously described [12]. The method is based on the antioxidants inhibition of the absorbance of the radical cation

*Corresponding author: Mancini A, Department of Medical Sciences, Division of Endocrinology, The Catholic University School of Medicine, Rome, Italy, Tel: +39-30154440; Fax: +39-0630157232; E-mail: me4224@mclink.it

Received June 03, 2013; Accepted July 22, 2013; Published July 30, 2013

Citation: Mancini A, Raimondo S, Di Segni C, Persano M, Cammarano M, et al. (2013) Effects of Intramuscular or Bioadhesive Buccal Testosterone Treatment on Antioxidant Systems in Secondary Hypogonadism. J Steroids Horm Sci 4: 117. doi:10.4172/2157-7536.1000117

Copyright: ( 2013 Mancini A, et al. This is an open-access article distributed under the terms of the Creative Commons Attribution License, which permits unrestricted use, distribution, and reproduction in any medium, provided the original author and source are credited. 
2,2 $2^{\mathrm{I}}$-azinobis (3-ethylbenzothiazoline-6 sulphonate) $\left(\mathrm{ABTS}^{+}\right)$formed by interaction between ABTS $(150 \mu \mathrm{M})$ and ferryl myoglobin radical species, generated by activation of meta myoglobin $(2.5 \mu \mathrm{M})$ with $\mathrm{H}_{2} \mathrm{O}_{2}(75 \mu \mathrm{M})$. Aliquots of the frozen plasma were thawed at room temperature and $10 \mu \mathrm{l}$ of the samples were tested immediately. The manual procedure was used with only minor modifications, i.e., temperature at $37^{\circ} \mathrm{C}$ to be in more physiological conditions and each sample assayed alone to carefully control timing and temperature. The reaction was started directly in cuvette through $\mathrm{H}_{2} \mathrm{O}_{2}$ addition after 1 min equilibration of all other reagents (temperature control by a thermocouple probe, model $1408 \mathrm{~K}$ thermocouple, Digitron Instrumentation Ltd, Scunthorpe, United kingdom) and followed for $10 \mathrm{~min}$ under continuous stirring, monitoring at $734 \mathrm{~nm}$, typical of the spectroscopically detectable ABTS ${ }^{+}$. The presence of chain-breaking antioxidants induces a lag time (the Lag phase) in the accumulation of $\mathrm{ABTS}^{+}$whose duration is proportional to the concentration of this type of antioxidants. Antioxidant capacity afforded by chainbreaking antioxidants is expressed as length of Lag phase (sec). Trolox, a water-soluble tocopherol analog, was used as a reference standard and assayed in all experiments to control the system. Absorbance was measured with a Hewlett-Packard 8450A UV/Vis spectrophotometer (Palo Alto, CA) equipped with a cuvette stirring apparatus and a constant temperature cell holder. Measurements of $\mathrm{pH}$ were made with a PHM84 Research pH meter (Radiometer, Copenhagen, Denmark,); the electrode response was corrected for temperature. Unless stated differently, experiments were repeated two to three times; qualitatively similar results were obtained with individual values varying $<8 \%$.

In the Lag mode, the assay mainly measures nonprotein and nonenzymatic antioxidants that are primarily extracellular chain breaking antioxidants, such as ascorbate, urate and glutathione [12].

\section{Statistics}

Distribution of data was estimated by the test of KolmogorovSmirnov. Since the data were not distributed normally, the comparison among groups was made using Mann-Whitney $\mathrm{U}$ test; the comparison in the same patients, before and after therapy was performed using Wilcoxon-Runk Sum test. Linear correlation analysis was also employed. The Software Arcus Quickstat (Software Publishing Biomedical version 1.2) was used for this statistic analysis.

\section{Results}

Hypogonadal patients, considered as a whole group, showed lower values of antioxidant systems than control subjects. The figure 1 shows mean \pm SEM CoQ10 values, significantly lower in hypogonadal patients $(0.66 \pm 0.07$ vs $0.93 \pm 0.11 \mu \mathrm{g} / \mathrm{ml}$ respectively, $\mathrm{p}<0.05)$. The figure 2 shows mean \pm SEM TAC values, expressed as LAG $(71 \pm 5.5$ vs $76 \pm$ $9.91 \mathrm{sec})$, with a trend toward lower levels in hypogonadal patients.

Testosterone treatment induced a change both in CoQ10 level $(0.81 \pm 0.43$ in group $\mathrm{A} ; 0.67 \pm 0.03 \mu \mathrm{g}$ in group B) and LAG $(78.33 \pm$ $4.53 \mathrm{sec}$ in group $\mathrm{A}$ and $80 \pm 4.03 \mathrm{sec}$ in group $\mathrm{B}$ ) (Table 1 ).

CoQ10 and LAG values significantly correlated $(\mathrm{r}=0,7 ; \mathrm{p}<0.001)$, when CoQ10 was corrected for cholesterol values (Figure 3 ), suggesting an inter-relationship between different antioxidants.

\section{Discussion}

Low testosterone levels may predict increased cardiovascular risk in men [13]. Moreover, treatment with exogenous testosterone improved arterial vasodilation [14] and lipid profile [15] in patients

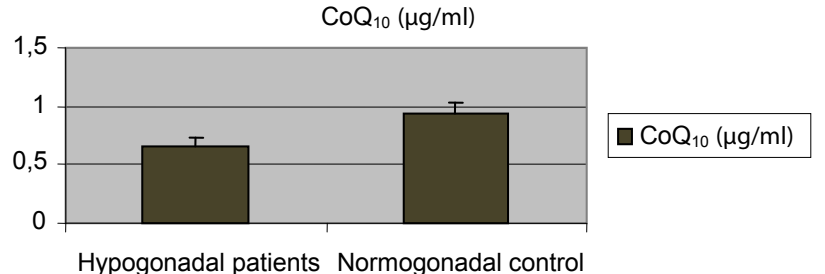

Figure 1: Mean ( \pm SEM) CoQ10 values in patients with secondary hypogonadism and normal controls.

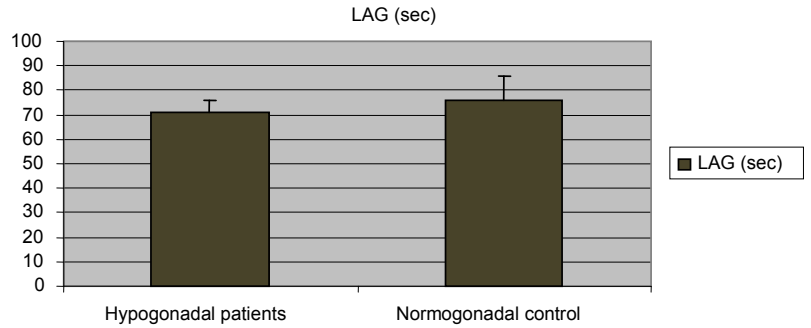

Figure 2: Mean ( \pm SEM) Total antioxidant capacity values, expressed as LAG, in patients with secondary hypogonadism and normal controls.

\begin{tabular}{|l|c|c|c|c|}
\hline & \multicolumn{2}{|c|}{ Group A } & \multicolumn{2}{c|}{ Group B } \\
\hline & Pretreatment & $\begin{array}{c}\text { Post treatment } \\
\text { Pre }\end{array}$ & Pretreatment & Post treatment \\
\hline $\begin{array}{l}\text { CoQ10 } \\
(\boldsymbol{\mu g} / \mathbf{m l})\end{array}$ & $0.65 \pm 0.21$ & $0.81 \pm 0.43$ & $0.43 \pm 0.06$ & $0.67 \pm 0.03$ \\
\hline $\begin{array}{l}\text { LAG } \\
(\mathbf{s e c})\end{array}$ & $56.66 \pm 4.08$ & $78.33 \pm 4.53$ & $56 \pm 8.16$ & $80 \pm 4.03$ \\
\hline
\end{tabular}

Table 1: Mean \pm SEM CoQ10 and LAG values, before and after treatment, in the two groups of patients, treated with different testosterone formulations.
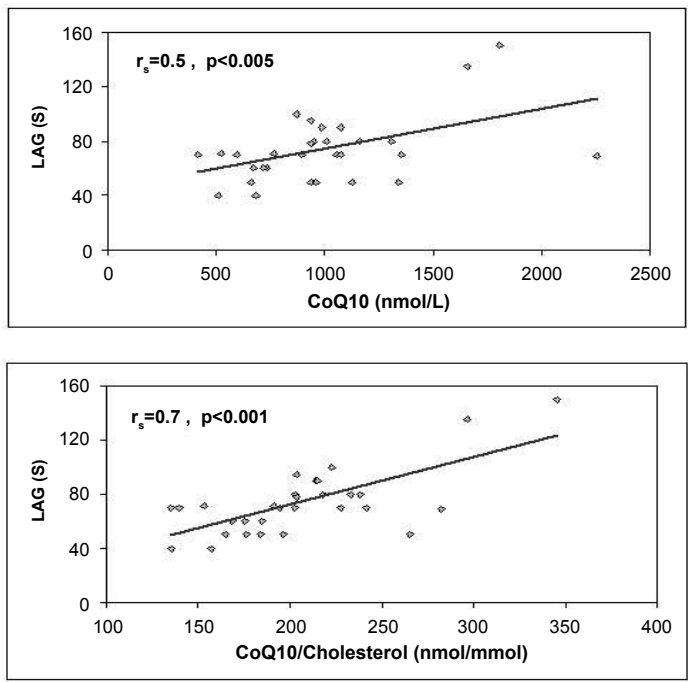

Figure 3: Graphical representation of simple regression analysis, plotting CoQ10 values (upper panel) or CoQ10/cholesterol values (lower panel) and LAG values in our patients.

with cardiovascular disease. In particular, testosterone induced a decrease of serum triglycerides, LDL cholesterol and an increase in HDL cholesterol. 
Oxidative stress could be a mechanism involved in progression of cardiovascular disease, in part for the oxidation of LDL-cholesterol [16], and in part for the activation of neutrophils, that contribute to ROS production through NADPH oxidase activation and release of myeloperoxidase, with a vicious circle inducing more toxic oxidant species. This mechanism can be counteracted by testosterone [17].

The role of androgens in the regulation of antioxidant systems is not fully understood. No significant effects of androgens were reported on antioxidant enzymes in erythrocytes [18]; conflicting results have also been reported about regulation of nitric oxide (NO) synthesis in immune system [19]; however antioxidant properties of testosterone in human neutrophils have been recently demonstrated, as indicated by suppression of superoxide anion and thiobarbituric acid-reactive substances (TBARS) levels, increase of NO levels, glutathione reductase activity and thiol groups; so testosterone administration at physiological concentrations had a greater antioxidant potential than higher concentrations [20].

Oxidative stress is claimed as responsible for toxicity and apoptosis of cardiomyocites induced by doxorubicin; in AR (androgen receptor)KO mice mitochondrial damage induced by the drug, with following ROS generation, is aggravated and the effect again counteracted by the system androgen-AR [21]. Castration induced an elevated prooxidant state in LV of adult Wistar rats, with a significant decrease of Superoxide Dismutase (SOD), Glutathione peroxidase (GPX), catalase (CAT), Glutathione Reductase (GR), and a trend toward lower levels of glutathione (GSH) and protein thiols, and an increase in lipid peroxidation and higher nitrotyrosine concentrations. The reestablishment of physiological $\mathrm{T}$ levels by androgen replacement resulted in a further decrease in the antioxidant defence [22].

Direct action at endothelial levels has been demonstrated [23]. Moreover testosterone attenuated expression of vascular cell adhesion molecule-1 by conversion to estradiol by aromatase [24]. Both in vitro and in vivo experiments also indicate direct testosterone effects on $\mathrm{NO}$ synthesis, and on tissue plasminogen activactor ( $\mathrm{t}-\mathrm{PA}$ ) and plasminogen activator inhibitor-I (PAI-I) expression. However differential effects are exerted by physiological or supraphysiological $\mathrm{T}$ doses.

Testosterone can have protective effects against oxidative stress in many other tissues and systems. OS causes $\beta$-cell apoptosis in streptozotocin-diabetic mice [25]; testosterone has been shown to exert a cytoprotective action in gonadectomized rats, inducing an increase in catalase and $\mathrm{Cu} / \mathrm{Zn} \mathrm{SOD}$; however this effect was sexspecific, inducible only in male rats, treated with testosterone, but not in female rats or male rats treated with estradiol or progesterone [26]. Another important site of action is central nervous system (CNS): testosterone protects cerebellar granule cells from oxidative stressinduced cell death by receptor-mediated mechanism [27], through an increase in catalase activity. Differential effects of glucocorticoid and gonadal steroids on glutathione levels were exerted in neuronal and glial cells: models of neuronal hippocampal cells (HT22) and glioma cells (C6) were tested and testosterone effects were also observed in long-term experiments [28]. The same group also showed increase in catalase activity after both short- and long-term incubation with gonadal steroids [29]. Testosterone was able to protect from OS and cell damage in the striatum, induced by ovariectomy (via caspase-3) and further increased by administration of 3-nitropropionic acid [30]. These studies are of fundamental importance for the investigation of neurodegenerative disorders, since OS has been implicated in the development of Alzheimer's disease, Parkinson disease and amyotrophic lateral sclerosis [31].
As genital apparatus is concerned, different studies have been performed on testis and prostate. Hypoxia exposure initiates low serum testosterone levels that could be attributed to down-regulated androgen biosynthesizing genes, such as StAR (steroidogenic acute regulatory protein) and $3-\beta-$ HSD (hydroxysteroid dehydrogenase) in the testis, associated with OS and increase in chaperones of endoplasmic reticulum, modulated by a reduction in calcium influx (ER stress) [32]. A protective effect was demonstrated for low dose testosterone supplementation in TM3 cell line (obtained by mouse and characterized by the presence of AR): significantly reduced ROS generation, lipid peroxide contents and hypoxia induction-factor (HIF)-1a stabilization and activation were found with 100 -nmol $\mathrm{l}^{-1}$ testosterone treatment; a 1.58 -fold increase in StAR expression was found in $50-\mathrm{nmol} \mathrm{l}^{-1}$; however there was a 1.72 -fold increase in ROS generation in the $500-\mathrm{nmol} \mathrm{l}^{-1}$, compared with the $100-\mathrm{nmol} \mathrm{l}^{-1}$ testosterone treatment [33].

Finally, androgens could exert an important role in the regulation of redox state in the prostate. It has been demonstrated that castration induced a discrete $O S$ in the acinar epithelium of rat ventral prostate (VP), as evidenced from marked increases in 8-hydroxy2'-deoxyguanosine and 4-hydroxynonenal protein adduct in the regressing epithelium [34]. Castration induced a dramatic increase of three ROS-generating $\mathrm{NAD}(\mathrm{P}) \mathrm{H}$ oxidases (Nox1, gp91phox and Nox4), a significant reduction of key ROS-detoxifying enzymes (SOD 2, GPX 1, thioredoxin, peroxiredoxin 5); catalase, glutathione reductase, $\gamma$-glutamyl trasnpeptidase, and glutathione synthetase levels remained unchanged. Testosterone replacement partially reduced OS in VP epithelia of castrated animals, however without restoring a fully normal pattern: it partially reduced expression of Noxs, but restored expression of SOD 2, GPX 1, thioredoxin, peroxiredoxin 5; moreover it induced a compensatory increase in expression of catalase, glutathione reductase, $\gamma$-glutamyl trasnpeptidase, and glutathione synthetase in the regenerating VP [35].

The present results, extending our previous data [9], confirm that hypogonadal patients present lower levels of antioxidant defence and therefore are more vulnerable to oxidative damage than normal eugonadal controls. The levels of CoQ10 were significantly lower, while TAC exhibited a trend toward lower levels.

TAC, as previously described [7], is a measurement of the nonenzymatic antioxidants that are primarily extracellular (ascorbate, urates, albumin, tocopherol and glutathione). They are "chainbreaking" molecules able to block the propagation chain of lipid peroxidation and to prevent the amplification of radical generation and the subsequent biochemical damage. Differently by enzymes, they are consumed at the moment in which they act and this fact could explain the reduction in their levels in biological fluids producing ROS (for example, the high levels of ROS and a low TAC in the seminal fluid of infertile males suggests oxidative stress is associated to a variety of etiologies of male infertility) [36]. The dosage of TAC is considered a better index of the total antioxidant status of a biological sample than the measurement of one or more specific antioxidant, that could not carefully reflect the combined effect of the various antioxidants and their "collaboration" during the oxidative stress. CoQ10 is a key component of the mitochondrial oxidative phosphorylation chain as link between flavoproteins and cytochromes in inner mitochondrial membrane. It has also many other functions, first of all a powerful antioxidant activity, and new roles in different cellular functions are coming out in last times, because this molecule can participate in oxido-reductive reactions not only in mitochondria, but also in 
Citation: Mancini A, Raimondo S, Di Segni C, Persano M, Cammarano M, et al. (2013) Effects of Intramuscular or Bioadhesive Buccal Testosterone Treatment on Antioxidant Systems in Secondary Hypogonadism. J Steroids Horm Sci 4: 117. doi:10.4172/2157-7536.1000117

lysosomial, in Golgi apparatus and plasmatic membranes [37], even contributing to membrane fluidity. Moreover CoQ10 can take part in many aspects of the oxido-reductive control of the cellular signalling origin and transmission; in fact the autooxidation of semi-quinon, formed in various membranes during the electronic transportation, can be a primary source for the $\mathrm{H} 2 \mathrm{O} 2$ generation, which activates some transcription factors, as NFkB, to induce gene expression [38].

We observed a significant direct correlation between CoQ10 and TAC in our patients, suggesting an important CoQ10 contribution to TAC and an inter-relationship between the different antioxidants. The greater impact on CoQ10 could be attributed to its lipophilic nature and the alterations of lipidic pattern in hypogonadal patients. There is a relationship between low concentrations of plasma CoQ10 and coronary disease, even if this correlation is not so strong to be considered a casual relation [39]. Ubiquinol/ubiquinone ratio is considered an oxidative stress marker in coronary disease and LDL/ CoQ10 ratio is an index of coronary risk factor [40]. Therefore our data underline, according to the protective role of ubiquinone in cardiovascular disease, a mechanism underlying the cardiovascular risk of hypogonadal patients.

Testosterone administration induced a significant increase in both parameters, independently from pharmacological route of adimistration, reinforcing the concept of a positive influence of testosterone per se on antioxidant systems.

In conclusion, the role of androgens in modulating the balance between ROS generation and antioxidant defences is very complex and related the different models investigated, time and dose of administration, different metabolic pathways of testosterone itself. Very few data are reported in vivo in humans. Our data allow to affirm that CoQ10 and TAC are significantly lower in secondary hypogonadic patients and that testosterone treatment exerts a positive effect on such values. Hypogonadism could represent a condition of oxidative stress, in turn related with augmented cardiovascular risk in such patients.

\section{References}

1. Kaufman JM, Vermeulen A (2005) The decline of androgen levels in elderly men and its clinical and therapeutic implications. Endocr Rev 26: 833-876.

2. Matsumoto AM (2002) Andropause: clinical implications of the decline in serum testosterone levels with aging in men. J Gerontol A Biol Sci Med Sci 57: M7699.

3. Rodriguez A, Muller DC, Metter EJ, Maggio M, Harman SM, et al. (2007) Aging androgens, and the metabolic syndrome in a longitudinal study of aging. $\mathrm{J} C$ Clin Endocrinol Metab 92: 3568-3572.

4. Vermeulen A (2001) Androgen replacement therapy in the aging male--a critical evaluation. J Clin Endocrinol Metab 86: 2380-2390.

5. Camacho EM, Huhtaniemi IT, O'Neill TW, Finn JD, Pye SR, et al. (2013) Ageassociated changes in hypothalamic-pituitary-testicular function in middle-aged and older men are modified by weight change and lifestyle factors: longitudinal results from the European Male Ageing Study. Eur J Endocrinol 168: 445-455.

6. Wu FC, von Eckardstein A (2003) Androgens and coronary artery disease Endocr Rev 24: 183-217.

7. Mancini A, Festa R, Di Donna V, Leone E, Littarru GP, et al. (2010) Hormones and antioxidant systems: role of pituitary and pituitary-dependent axes. J Endocrinol Invest 33: 422-433.

8. Mancini A, Festa R, Silvestrini A, Nicolotti N, Di Donna V, et al. (2009) Hormona regulation of total antioxidant capacity in seminal plasma. J Androl 30: 534-540.

9. Mancini A, Leone E, Festa R, Grande G, Silvestrini A, et al. (2008) Effects of testosterone on antioxidant systems in male secondary hypogonadism. J Androl 29: 622-629.

10. Littarru GP, Tiano L (2005) Clinical aspects of coenzyme Q10: an update. Curr Opin Clin Nutr Metab Care 8: 641-646.
11. Rice-Evans C, Miller NJ (1994) Total antioxidant status in plasma and body fluids. Methods Enzymol 234: 279-293.

12. Meucci E, Milardi D, Mordente A, Martorana GE, Giacchi E, et al. (2003) Total antioxidant capacity in patients with varicoceles. Fertil Steril 79 Suppl 3: 15771583.

13. Svartberg J, von Mühlen D, Mathiesen E, Joakimsen O, Bønaa $\mathrm{KH}$, et al (2006) Low testosterone levels are associated with carotid atherosclerosis in men. J Intern Med 259: 576-582.

14. Webb CM, McNeill JG, Hayward CS, de Zeigler D, Collins P (1999) Effects of testosterone on coronary vasomotor regulation in men with coronary heart disease. Circulation 100: 1690-1696.

15. Wu S, Weng $X$ (1992) Therapeutic effect of andriol on serum lipids and apolipoproteins in elderly male coronary heart disease patients. Chin Med Sci J 7: 137-141.

16. Griendling KK, Sorescu D, Ushio-Fukai M (2000) NAD(P)H oxidase: role in cardiovascular biology and disease. Circ Res 86: 494-501.

17. Békési G, Kakucs R, Várbíró S, Rácz K, Sprintz D, et al. (2000) In vitro effects of different steroid hormones on superoxide anion production of human neutrophil granulocytes. Steroids 65: 889-894.

18. Massafra C, Gioia D, De Felice C, Picciolini E, De Leo V, et al. (2000) Effects of estrogens and androgens on erythrocyte antioxidant superoxide dismutase, catalase and glutathione peroxidase activities during the menstrual cycle. Endocrinol 167: 447-452.

19. Friedl R, Brunner M, Moeslinger T, Spieckermann PG (2000) Testosterone inhibits expression of inducible nitric oxide synthase in murine macrophages. Life Sci 68: 417-429.

20. Marin DP, Bolin AP, dos Santos Rde C, Curi R, Otton R (2010) Testosterone suppresses oxidative stress in human neutrophils. Cell Biochem Funct 28: 394 402.

21. Ikeda Y, Aihara K, Akaike M, Sato T, Ishikawa K, et al. (2010) Androgen receptor counteracts Doxorubicin-induced cardiotoxicity in male mice. Mo Endocrinol 24: 1338-1348.

22. Kłapcińska B, Jagsz S, Sadowska-Krepa E, Górski J, Kempa K et al. (2008) Effects of castration and testosterone replacement on the antioxidant defense system in rat left ventricle. J Physiol Sci 58: 173-177.

23. Campelo AE, Cutini PH, Massheimer VL (2012) Testosterone modulates platelet aggregation and endothelial cell growth through nitric oxide pathway. $J$ Endocrinol 213: 77-87.

24. Mukherjee TK, Dinh H, Chaudhuri G, Nathan L (2002) Testosterone attenuates expression of vascular cell adhesion molecule-1 by conversion to estradiol by aromatase in endothelial cells: implications in atherosclerosis. Proc Natl Acad Sci U S A 99: 4055-4060.

25. O'Brien BA, Harmon BV, Cameron DP, Allan DJ (1996) Beta-cell apoptosis is responsible for the development of IDDM in the multiple low-dose streptozotocin model. J Pathol 178: 176-181.

26. Palomar-Morales M, Morimoto S, Mendoza-Rodríguez CA, Cerbón MA (2010) The protective effect of testosterone on streptozotocin-induced apoptosis in beta cells is sex specific. Pancreas 39: 193-200.

27. Ahlbom E, Prins GS, Ceccatelli S (2001) Testosterone protects cerebellar granule cells from oxidative stress-induced cell death through a receptor mediated mechanism. Brain Res 892: 255-262.

28. Schmidt AJ, Krieg J-, Vedder H (2002) Differential effects of glucocorticoids and gonadal steroids on glutathione levels in neuronal and glial cell systems. $J$ Neurosci Res 67: 544-550.

29. Schmidt AJ, Krieg JC, Vedder H (2005) Effects of steroid hormones on catalase activity in neuronal and glial cell systems. Eur Neuropsychopharmacol 15: 177183

30. Túnez I, Feijóo M, Collado JA, Medina FJ, Peña J, et al. (2007) Effect of testosterone on oxidative stress and cell damage induced by 3-nitropropionic acid in striatum of ovariectomized rats. Life Sci 80: 1221-1227.

31. Barron AM, Fuller SJ, Verdile G, Martins RN (2006) Reproductive hormone modulate oxidative stress in Alzheimer's disease. Antioxid Redox Signal 8 . 2047-2059.

32. Liu GL, Yu F, Dai DZ, Zhang GL, Zhang C, et al. (2012) Endoplasmic reticulum 
Citation: Mancini A, Raimondo S, Di Segni C, Persano M, Cammarano M, et al. (2013) Effects of Intramuscular or Bioadhesive Buccal Testosterone Treatment on Antioxidant Systems in Secondary Hypogonadism. J Steroids Horm Sci 4: 117. doi:10.4172/2157-7536.1000117

stress mediating downregulated StAR and 3-beta-HSD and low plasma testosterone caused by hypoxia is attenuated by CPU86017-RS and nifedipine. J Biomed Sci 19: 4

33. Hwang TI, Liao TL, Lin JF, Lin YC, Lee SY, et al. (2011) Low-dose testosterone treatment decreases oxidative damage in TM3 Leydig cells. Asian J Androl 13: 432-437.

34. Kohen R, Nyska A (2002) Oxidation of biological systems: oxidative stress phenomena, antioxidants, redox reactions, and methods for their quantification. Toxicol Pathol 30: 620-650.

35. Tam NN, Gao Y, Leung YK, Ho SM (2003) Androgenic regulation of oxidative stress in the rat prostate: involvement of $\mathrm{NAD}(\mathrm{P}) \mathrm{H}$ oxidases and antioxidan defense machinery during prostatic involution and regrowth. Am J Pathol 163 2513-2522.
36. Lewis SE, Boyle PM, McKinney KA, Young IS, Thompson W (1995) Total antioxidant capacity of seminal plasma is different in fertile and infertile men. Fertil Steril 64: 868-870.

37. Crane FL (2001) Biochemical functions of coenzyme Q10. J Am Coll Nutr 20: 591-598.

38. Kaltschmidt B, Sparna T, Kaltschmidt C (1999) Activation of NF-kappa B by reactive oxygen intermediates in the nervous system. Antioxid Redox Signal 1: $129-144$.

39. Yalcin A, Kilinc E, Sagcan A, Kultursay H (2004) Coenzyme Q10 concentrations in coronary artery disease. Clin Biochem 37: 706-709.

40. Tomasetti M, Alleva R, Solenghi MD, Littarru GP (1999) Distribution of antioxidants among blood components and lipoproteins: significance of lipids/CoQ10 ratio as a possible marker of increased risk for atherosclerosis. Biofactors 9: 231-240. 